\title{
An Investigation into the Use of an Herbal Labor Induction Tincture Containing Black Cohosh, Cramp Bark, Partridgeberry, and Motherwort on Contractile Responses Produced from Isolated Strips of Mouse Uterine Tissues
}

\author{
Clayton Neuenschwander ${ }^{1, *}$, Katrina $\mathrm{Wu}^{2}{ }^{2}$, Teresa DeGolier ${ }^{1}$
}

Clayton Neuenschwander ${ }^{1, *}$, Katrina $\mathrm{Wu}^{2}{ }^{2}$, Teresa DeGolier ${ }^{1}$

'Department of Biological Sciences, 3900 Bethel Drive, Bethel University, St. Paul, MN 55112, USA.

${ }^{2}$ Nursing Department, 3900 Bethel Drive

Bethel University, St. Paul, MN 55112, USA.

\section{Correspondence}

\section{Clayton Neuenschwander}

Department of Biological Sciences, 3900 Bethel Drive, Bethel University, St. Paul, MN 55112, USA.

E-mail: cln39894@bethel.edu

History

- Submission Date: 20-08-2021;

- Review completed: 29-08-2021;

- Accepted Date: 02-09-2021.

DOI : 10.5530/pj.2021.13.188

Article Available online

http://www.phcogj.com/v13/i6

\section{Copyright}

(c) 2021 Phcogj.Com. This is an openaccess article distributed under the terms of the Creative Commons Attribution 4.0 International license.

\begin{abstract}
Introduction: Alternative solutions in the form of herbal remedies meant to ease or expedite the process of labor have often been pursued and administered but have seldom been quantitatively tested for efficacy Published research has shown some validation for some commonly used herbs such as blue cohosh (Caulophyllum thalictroides), red raspberry (Rubus idaeus), castor bean (Ricinus communis) and evening primrose (Oenothera biennis) on isolated mouse uterine strips. Methods: This study tested an array of herbs used by midwives in a labor induction tincture, which included black cohosh (Actaea racemosa), cramp bark (Viburnum opulus), partridgeberry (Mitchella repens), and motherwort (Leonurus cardiaca). Each of these four herbs were prepared as aqueous extracts and applied individually to uterine tissues in an organ bath apparatus. Results: Results and analyses indicated that all treatment tissues produced significant increases in contractile forces when compared to their own endogenous motilities $(p<0.0001)$. These responses, however, were not significantly different among the four herbal treatments, but were comparable to those produced by $10^{-5} \mathrm{M}$ oxytocin. Conclusions: This study provides empirical support for the use of these plants as herbal uterotonics, and it is plausible that these results, collected in vitro, may support the use of such a tincture to enhance or augment labor in vivo. Consideration of the active constituents found in each herbal, their concentrations, solubilities, cell signalling pathways, and the potential to interact in a synergistic or attenuating manner would be beneficial prior to recommending a given herbal for use at an organismal level.
\end{abstract}

Key words: Complimentary therapies; Herbal medicine; Labor, Induced; Midwifery; Oxytocics.

\section{INTRODUCTION}

In an effort to promote maternal and fetal wellbeing, labor induction and labor augmentation have become integral parts of childbirth around the world, with labor induction rates ranging from $8-36 \%$ in high-income countries and generally somewhat lower in low- and middle-income

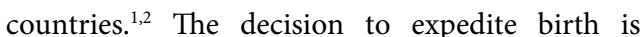
made when the risks of remaining pregnant are generally understood to pose more risk than the potential for compromising a fetus' adequate oxygenation by increasing uterine contractility. ${ }^{3}$ Oxytocin is the primary medication given to induce uterine contractions; and it is often given alongside a mechanical cervical dilator or a prostaglandin drug for cervical ripening. ${ }^{3,4}$ As oxytocin has the potential to hyperstimulate the uterus when administered during labor, it must be given in a hospital setting capable of continuously monitoring both contractions and the fetal heart rate. ${ }^{3}$ However, in community birth settings, such as the home environment and free-standing birth centers, alternative approaches to oxytocin are often utilized, including breast stimulation, homeopathics, acupuncture, herbal medicine, and aromatherapy. ${ }^{5-7}$

Complementary and alternative therapies have been used in pregnancy and birth for centuries, particularly by midwives, and interest in their use continues to grow among pregnant people. ${ }^{8-12}$ Some patients may opt for these more natural therapeutic modalities for induction in an attempt to avoid any perceived or established adverse effects associated with a medical induction, including a reduced maternal satisfaction, increased labor pain, increased use of analgesia, fetal distress, the need for increased fetal monitoring with potential for accompanying mobility limitations during labor, an increased need for subsequent interventions in labor, and the need to deliver in a hospital setting. ${ }^{13-15}$

Research on the safety and effectiveness of natural modalities is limited, often originating from in vivo surveys or observational studies and lacking definitive scientific support. In a survey on herbal use among midwives practicing in California in the United States, peer midwives were cited most frequently as a source of herbal information (25$27 \%$ of respondents), with peer-reviewed research only being cited by $15-17 \%$ of respondents. ${ }^{12}$ There are several in vitro studies, which have demonstrated strong uterine contractile responses to herbal preparations when employing isolated issues in organ baths. For example, individual aqueous extracts from the roots and rhizomes of blue cohosh Caullophylum thalactroides ${ }^{16}$, red raspberry leaves Rubus ideaus ${ }^{17}$, castor beans Ricinus communis ${ }^{18}$, evening primrose seeds Oenothera biennis ${ }^{19}$, and clary sage Salvia 
sclarea $^{20}$ have all been shown to produce strong contractile responses in isolated mouse uterine tissues similar to those evoked following an application of $10^{-5} \mathrm{M}$ oxytocin. In all cases, the uterine contractile responses to these treatments were statistically greater than those of the controls $(p<0.05)$, or the " 0 " treatment, which is the endogenous, spontaneous rhythmicity of the uterine tissue itself when under a given amount of tension. ${ }^{21}$ The ability to initiate or augment labor by chemical means is a necessary element of providing birth services, so identifying substances that can produce a typical response in a specified dosage is an important step to being able to ultimately confirm both efficacy and safety of these substances in pregnant populations.

The purpose of this study was to investigate the biological activities of the herbal constituents as labelled within a unique midwifery herbal induction tincture obtained from a freestanding birthing center. This tincture contained equal parts of Actaea racemosa (black cohosh), Viburnum opulus (cramp bark), Mitchella repens (partridgeberry), and Leonurus cardiaca (motherwort), dissolved in organic alcohol, spring water, and vegetable glycerate. The main objective was to determine whether each of the individual constituents, administered as separate aqueous extracts, had the ability to promote contractility in isolated smooth muscle tissues collected from mice uteri. A second objective was to consider how the results collected in vitro could provide support for the use of such a tincture to enhance or augment labor in vivo.

\section{MATERIALS AND METHODS}

\section{Animal specimens}

Twenty-one virgin female mice, Mus musculus (outbred ICR CD-1) each weighing 25-30 grams, were obtained from Envigo, Inc. (Indianapolis, Indiana, USA). They were housed in cages in the Department of Biological Sciences at Bethel University (St. Paul, Minnesota, USA) and had access to water and standard mice chow ad libitum. All experimental procedures were completed in compliance with the Institutional Animal Care and Use Committee of Bethel University.

\section{Preparation of uterine tissues}

Twenty-four hours before uterine horn tissue extraction, mice were given an injection of diethylstilboestrol (DES) in the abdominopelvic cavity. DES is a non-steroidal synthetic oestrogen receptor agonist commonly used to promote the mouse into the oestrus stage of its oestrous cycle. ${ }^{22}$ DES increases the number of gap junctions in the uterine tissue and allows the uterus to contract more effectively as a single unit. ${ }^{23,24}$

On the day of the procedure, fresh DeJalons solution (g/5L: $45 \mathrm{~g} \mathrm{NaCl}$, 2.1g KCL, 2.5 $\mathrm{g} \mathrm{NaHCO}_{3}, 2.5 \mathrm{~g} \mathrm{D}$-glucose, and $0.4 \mathrm{~g} \mathrm{CaCl}_{2}$ ) was prepared to simulate extracellular M. musculus fluid conditions. Mice were euthanized via $\mathrm{CO}_{2}$ asphyxiation and pinned to a dissection board. The abdominopelvic cavity was accessed by $4 \mathrm{~cm}$ incision, made cranially from the vaginal orifice, and the uterine tissue was removed. The two uterine horns were obtained per mouse, isolated, and a suture was tied to each end; one suture for attachment to a stationary rod to be placed in the $20 \mathrm{~mL}$ organ bath, and the other for attachment to an isometric force transducer (MLT500, ADInstruments, Colorado Springs, Colorado, USA).

At the start of each experiment, the organ baths were flushed with DeJalons solution $\left(32^{\circ} \mathrm{C}\right)$. A prepared uterine horn was lowered into the organ bath (Figure 1), and subsequently tightened to $0.8 \mathrm{~g}$ tension. ${ }^{25}$ The isometric force transducers were connected to a PowerLab data acquisition system (ADInstruments, Colorado Springs, Colorado, USA) which collected and compiled the contractile activity data into visual waveforms for analysis. Over the course of the experiment, the baths were continuously aerated with $95 \% \mathrm{O}_{2} / 5 \% \mathrm{CO}_{2}$ at $\sim 2 \mathrm{psi}$, and tissues were routinely flushed (tissue washouts) to remove metabolites.

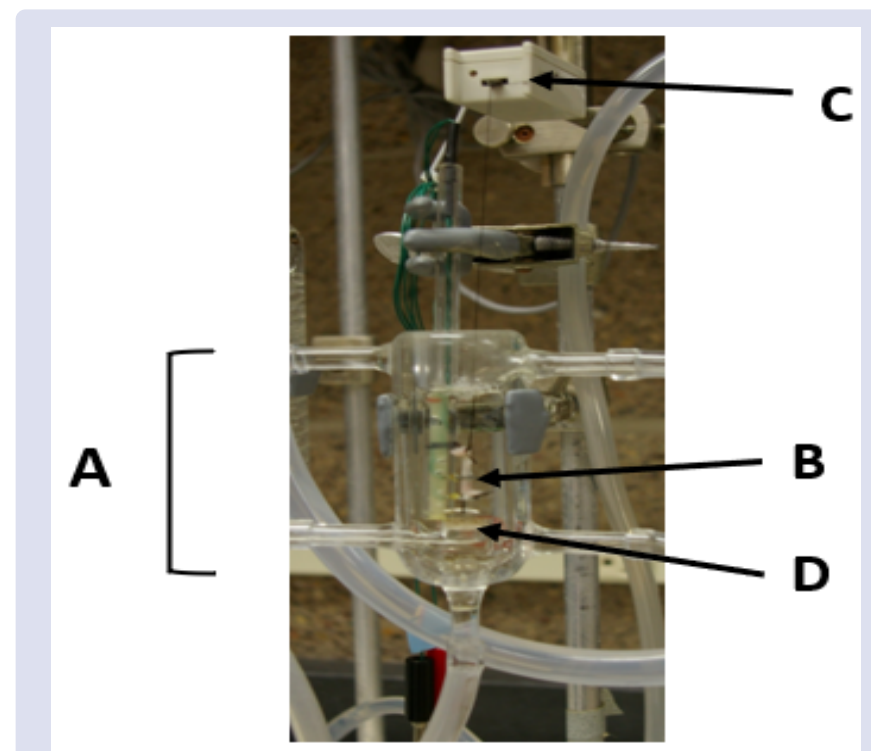

Figure 1. A single organ bath (letter " $A$ ") containing $20 \mathrm{~mL}$ of DeJalons solution. An isolated uterine horn (letter " $\mathrm{B}$ ") is suspended via a ligature to an isometric force transducer (letter " $\mathrm{C}$ ") and to a stationary rod at letter " $\mathrm{D}$ ", which acted to anchor the tissue in a vertical orientation within the organ bath.

(Photo courtesy of GL DeGolier).

The uterine horns were equilibrated for one hour with four flushes in 15-minute intervals to replenish the organ baths with fresh DeJalons solution. During this time, the tissues typically demonstrated some level of spontaneous motility (an endogenous smooth muscle contraction rhythmicity) representative of healthy uterine smooth muscle under tension. ${ }^{21,25}$

\section{Preparation of herbal extracts}

Stocks of the four experimental herbs (Actaea racemosa, Viburnum opulus, Mitchella repens, Leonurus cardiaca) were obtained as dried cuttings from Richters Herbs (Goodwood, Ontario, Canada). Each herbal sample was individually ground with a coffee grinder, and a given mass of $4,050 \mathrm{mg}$ was then added to $100 \mathrm{~mL}$ boiling DI water to steep overnight. ${ }^{26,27}$ Individual herbal samples were then vacuum filtrated through Whatman filter papers via a Buchner funnel 16 hours after the steep was initiated, and the subsequent solutions (the aqueous extracts) were set on stir plates until the addition point of the procedure. The non-filtrate remaining was allowed to dry in the open air over 72 hours. These dried residues were massed and their values were subtracted from the initial masses to yield a final calculated herbal concentration for black cohosh, partridgeberry, and motherwort to be $0.5 \mathrm{mg} / \mathrm{ml}$ in an organ bath. The final concentration for cramp bark was $0.3 \mathrm{mg} / \mathrm{ml}$, possibly due to a decrease in solubility as a function of its potential constituents.

All other chemicals were purchased from Sigma-Aldrich (St. Louis, Missouri, USA).

\section{Experimental protocol}

After the initial equilibration period, $10^{-5} \mathrm{M}$ oxytocin, serving as a positive uterine contractile control ${ }^{28}$ was pipetted directly into each organ bath. The resulting uterine tissue contracture was recorded for ten minutes. Then each bath was thoroughly flushed with fresh DeJalons solution 1-2 times, and allowed to return to its spontaneous rhythm as observed before the addition of an herbal treatment. A given volume of the prepared herbal sample was pipetted into each tissue bath 10-15 min later. Tissue activity was again recorded for at least 1520 minutes to allow for a clear pattern of contractility to emerge. 
Neuenschwander C, et al.: An Investigation into the Use of an Herbal Labor Induction Tincture Containing Black Cohosh, Cramp Bark, Partridgeberry, and Motherwort on Contractile Responses Produced from Isolated Strips of Mouse Uterine Tissues

\section{Measurements}

Treatment applications were given under baseline tissue tensions and between any observed spontaneous activities. Changes in contractile forces $(\mathrm{mN})$ were measured by taking the difference between the baseline tension and the maximal force of a tissue contracture produced by a treatment. To control for the contribution that spontaneous motility may have had on the treatment contractile response, spontaneous motility amplitudes were also measured in a similar fashion (before the point of treatment) and were considered as the control or " 0 " treatment.

Every attempt was made to keep the amount of smooth muscle consistent while extracting the uterine horns and suspending them in the organ bath. To normalize for any slight variation in the uterine tissue masses, the maximal contractile response of each individual tissue to any given treatment (herbal or spontaneous motility) was expressed as a percent of its initial contractile response to its positive control, oxytocin (\% oxytocin).

\section{Statistical analyses}

The contractile force data was summarized as the means \pm standard error of the mean (SEM) for each herbal treatment. A clustered column chart was used to show values (means \pm SEM) across the herbal species.

A One-Way Analysis of Variance (ANOVA) was used to make comparisons among the means of the five treatments (spontaneous motility, Actaea racemosa, Viburnum opulus, Mitchella repens, and Leonurus cardiaca). If the resulting $p$-value was $\leq 0.05$, then a TukeyKramer post-hoc test (JMP 4.0, SAS Institute, Cary, NC) was utilized to find which herbal contractile mean responses differed significantly from each other.

The contractile force data (\% oxytocin) was also summarized and presented as box and whisker plots to further illustrate the shape of the data distribution, their central values and variations.

\section{RESULTS}

\section{Uterine smooth muscle contractile responses to oxytocin}

Tissue viability was affirmed by the presence of spontaneous motility and a response to $10^{-5} \mathrm{M}$ oxytocin. Tissues that did not exhibit immediate spontaneous motility during the pretreatment $60 \mathrm{~min}$ equilibration period, did indeed present these endogenous rhythms after the application of oxytocin.

Figure 2 shows an example of the typical waveforms produced from a uterine tissue, including spontaneous motility as well as responses to both oxytocin and a partridgeberry extract over the course of an experiment ( $\sim 90$ minutes). In this sample, oxytocin applied at letter " $A$ ", generated an increase in contractile force of $26.6 \mathrm{mN}$ that was sustained until the tissue bath experienced a washout (see dotted line). In most cases, baseline tensions returned within $20 \mathrm{~min}$ to those similar to pre-oxytocin levels. Frequently, as a result of the oxytocin contractile signalling mechanism, the returning baseline did demonstrate an increase in amplitude of the tissues own spontaneous motility. In this sample, the application of a $0.5 \mathrm{mg} / \mathrm{ml}$ partridgeberry extract applied at letter "B" resulted in an immediate non-sustained increase in contractile force of $36.7 \mathrm{mN}$, representing a force of $137 \%$ of the of oxytocin control response.

Temporary increases in uterine contractile frequency as well as modest increases in basal tonus (baseline tension) were sometimes observed following any given herbal application. These contractile patterns eventually returned to their waveform patterns similar to those observed prior to herbal applications. Only the changes in contractile forces are reported herein as they were the most repeatable.

\section{Uterine smooth muscle contractile responses to the individual herbal treatments}

The average actual physical contractile force $(\mathrm{mN})$ produced from the black cohosh herbal treatments was $28.26 \pm 2.89 \mathrm{mN}(\mathrm{n}=4)$; from cramp bark was $18.33 \pm 5.53 \mathrm{mN}(\mathrm{n}=4)$; from partridgeberry was 33.70 $\pm 2.0 \mathrm{mN}(\mathrm{n}=4)$ and from motherwort was $26.66 \pm 4.57 \mathrm{mN}(\mathrm{n}=4)$. The average force produced by oxytocin was $26.91 \pm 5.24 \mathrm{mN}(\mathrm{n}=16)$, and the tissue endogenous rhythm (" 0 " treatment) was $7.24 \pm 1.84 \mathrm{mN}$ $(n=16)$.

Figure 3 shows the means ( \pm SEM) uterine contractile forces (\% oxytocin) in response to the individual herbal preparations listed in the herbal induction supplement. Each herbal preparation significantly increased contractile forces as compared to the average spontaneous motility control $(p<0.0001)$. However, the four herbal treatment contractile responses themselves were not significantly different from each other.

Both partridgeberry and black cohosh produced contractile responses greater than their oxytocin controls (140\% and 115\%, respectively). Crampbark and motherwort contractile responses were still very powerful, but both were less forceful than their oxytocin controls $(90 \%$ and $94 \%$, respectively), and in contrast to partridgeberry and black cohosh, both demonstrated a larger amount of variation around their mean responses (Figure 3).

The same data presented in Figure 3 is also presented in Figure 4 as a variety of box and whisker plots with different shapes and positions along the $\mathrm{Y}$-axis. The box plots for both black cohosh and partridgeberry are comparatively short, indicating that the range of their respective contractile responses is very narrow. Their median quartile responses are also very close to their mean contractile responses. In contrast, the box plots for cramp bark and motherwort, as well as the experimental

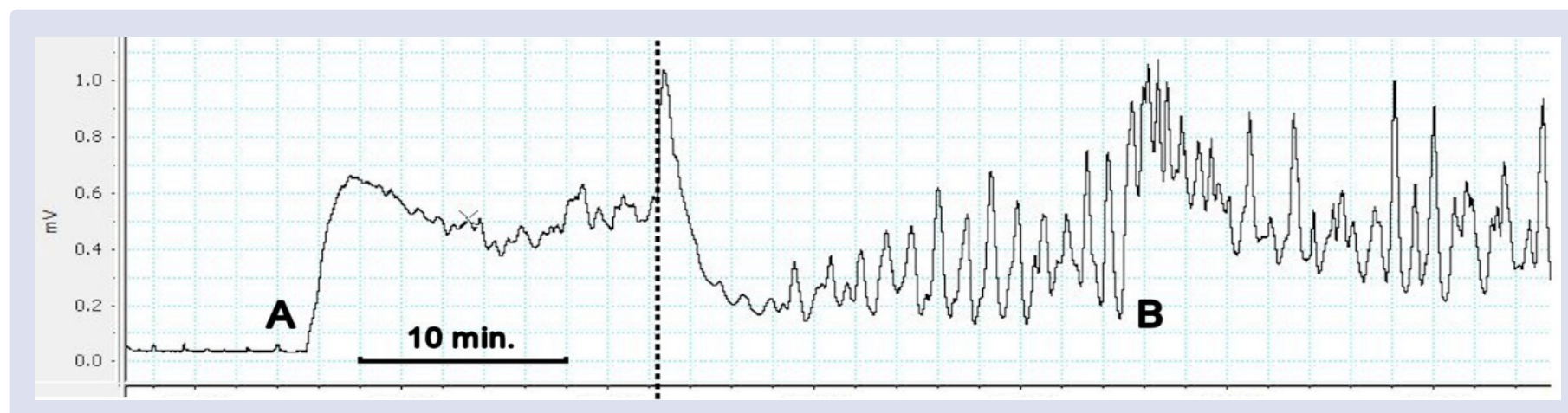

Figure 2. Typical uterine smooth muscle waveform contractile pattern before and after an application of 10-5 M oxytocin (letter "A") followed by a sample $0.5 \mathrm{mg} / \mathrm{ml}$ partridgeberry treatment (letter "B"). The vertical axis represents contractile force in $\mathrm{mV}$, later converted to $\mathrm{mN}$. 


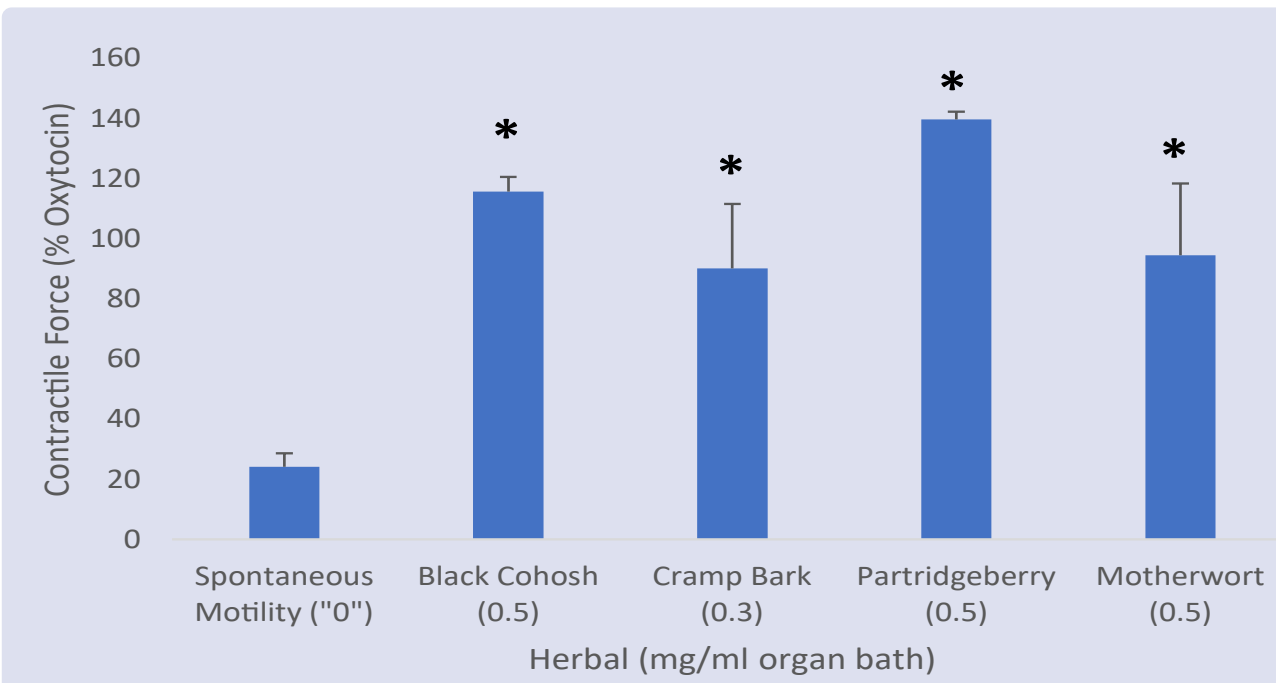

Figure 3. Means ( \pm SEM) of uterine contractile forces (\% oxytocin) in response to the individual herbals listed in the herbal induction supplement. Each herbal treatment significantly increased contractile forces $\left(^{*}\right)$ as compared to the average spontaneous motility control $(p<0.0001)$.

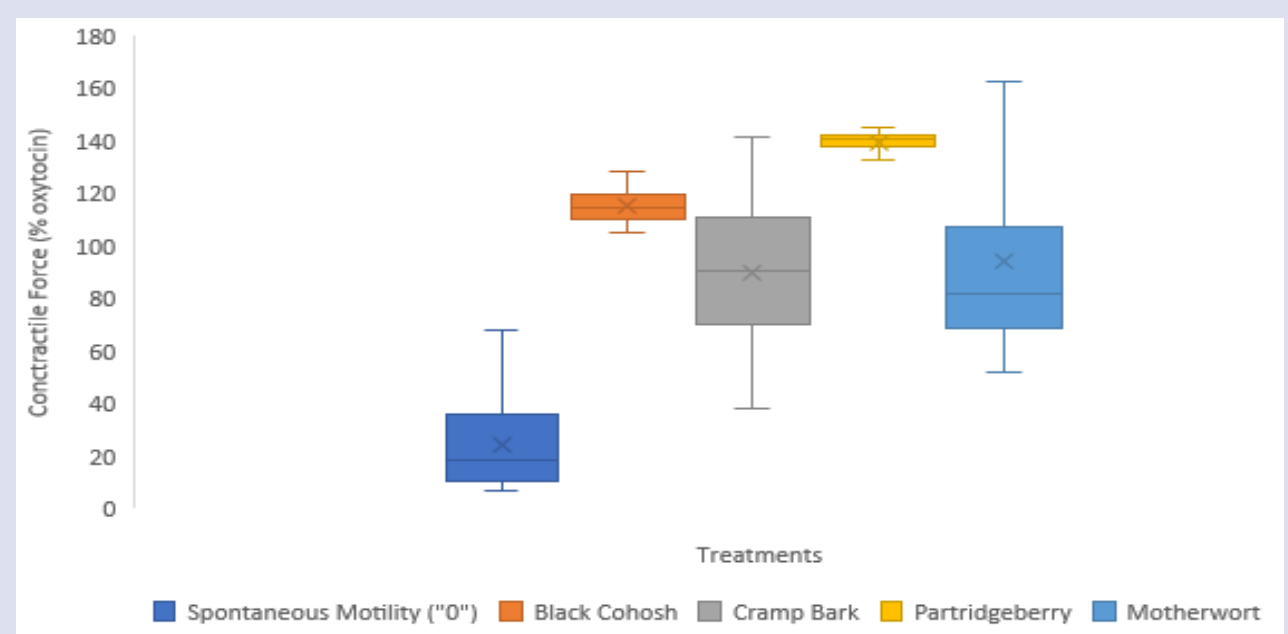

Figure 4. Shows box and whisker plots (upper and lower whiskers, lower, middle, and upper quartiles) summarizing the unique distribution of uterine smooth muscle contractile responses from the four herbals tested as well as their " 0 " treatment control. The " $X$ " inside each box plot represents the contractile mean. Contractile forces are expressed as a percent of the oxytocin control. There were no outliers for this data.

controls, show very different distributions. These longer box plots indicate more variation within their respective contractile responses. While the cramp bark medium quartile is essentially the same as its contractile mean, the medium quartile for motherwort $(81.7 \%$ oxytocin) is quite a bit lower than its respective contractile mean $(94 \%$ oxytocin). The long upper whisker (quartile group 4) indicates that $75 \%$ of the contractile responses produced by motherwort were quite variable. In like manner, the short lower whisker (quartile group 1) indicates that $25 \%$ the contractile responses produced by motherwort were very consistent. The respective inter-quartile range for black cohosh, cramp bark, and partridgeberry are much more consistent relative to their individual middle quartile.

\section{DISCUSSION}

The application of each individual herbal ingredient of the labor induction tincture to isolated mouse uterine tissues resulted in significant increases in contractile forces as compared to the tissues' own spontaneous motility. These findings thus support the use of the herbal induction tincture from an efficacy standpoint, recognizing that this study was conducted on in vitro mice uteri and not in vivo humans. Since there were no statistical differences between the forces produced among the four individual herbal treatments, there may be a justification for using any of these herbals as part of a management approach to induction instead of oxytocin to induce or at the very least, augment a prolonged labor.

Both black cohosh and partridgeberry produced uterine contractile forces greater than cramp bark and motherwort (Figure 3). This would seem consistent with information gleaned from reviews of the literature, herbal handbooks, and reports of traditional use. For example, black cohosh is stated to help the uterus contract in a coordinated and effective way, ${ }^{29,30,32}$ and was used by $28 \%$ of Certified Nurse-Midwives/ Certified Midwives and $66 \%$ of Licenced Midwives who reported using herbs in their practice in a survey of California midwives $(\mathrm{N}=139)$ in the United States. ${ }^{12}$ In like manner, the use of partridgeberry is considered as safe during labor; it is considered to tone and strengthen the uterus, resulting in more uniform uterine contractions. ${ }^{29-31,33,34}$ 
Motherwort is said to be a fine uterotonic as it promotes a calming influence, relieves pain, and prevents miscarriage. ${ }^{29}$ However, even though some sources report that motherwort can be used safely during pregnancy and to ease birth, ${ }^{29,33}$ is has also been reported to be unsafe for use during pregnancy as it may cause birth defects. ${ }^{34}$ Cramp bark, the remaining herbal ingredient in the labor induction tincture, has not been historically reported as a uterotonic. Instead, it is claimed to sedate the uterus and reduce the pains caused by uterine contractions. ${ }^{29}$

A large volume of ongoing research done on medicinal herbs targets the identification and isolation of their respective biologically active constituents. $^{35-38}$ The resulting information has primarily been used to determine whether the constituents have potential as antiinflammatory, antioxidant, antibacterial, antifungal, and antiviral agents. ${ }^{39-42} \mathrm{~A}$ majority of published results have been completed making use of in vitro studies, as it is challenging to investigate and interpret potential results at an organismal level due to the complex interactions of multicellular systems. ${ }^{43}$ Opportunistically, it has become evident that several of these same active constituents may also be responsible for the changes in uterine smooth muscle contractile behaviours. ${ }^{44}$

There are several reasons why knowing the biologically active constituents of the individual herbals used in the labor induction tincture investigated herein would be useful to both researchers and health care practitioners. An initial consideration is the understanding of whether or not herbals that behave similarly to each other (e.g. Figure 3) have the same biologically active constituents. These phytochemicals, or secondary plant metabolites, include saponins, terpenes, alkaloids, and phenolics. They are important in traditional medicine, and have frequently led to the production of modern medications. ${ }^{45}$

Another consideration is the availability of these phytochemicals based on the nature of the investigative protocol used to understand their biological activity. For example, conditions within an in vitro experiment (such as the organ bath study reported herein) are different from the unique clinical setting, where herbals would be consumed, absorbed, and presumably interact with receptors on the uterus. Many changes to the active compounds are likely to occur over the intestinal and circulatory journey, and they simply might not arrive at the target tissue receptors.

In the experiment reported herein, a goal was to utilize an aqueous extract that would most closely mimic that which would be orally consumed as a given mass of dry herbal plant tissues dissolved in water. It was observed during our investigation, that the applied extract remained water soluble as there was no evidence of a hydrophobic partition settling to the top of the organ bath. Thus, it could be reasoned that most of the lipophilic constituents were contained within the nonfiltered residue, and it was the hydrophilic constituents of these plant extracts that were involved in the contraction of the uterine tissues. Solubility differences among the constituents may also influence how the results among the same herbals can vary. For example, black cohosh has received considerable attention in the treatment of menopause ${ }^{46}$, possibly due to the lipophilic constituents binding to oestrogen receptor subtypes. ${ }^{47}$ Black cohosh has been thought to exert its effects akin to that of a selective agonist of certain oestrogen receptor sites and as an antagonist of others. ${ }^{48}$ This would seem significant, as any change in oestrogen reception has varying effects on labor processes, depending on the receptor sites affected. However, in animal laboratory studies, black cohosh has not been demonstrated to interact with oestrogen receptors. ${ }^{49}$

Nevertheless, it is the lipid constituents in black cohosh are considered to be responsible for an inhibition of rat uterine contractions in vitro that were precontracted with oxytocin, prostaglandin, or bradykinin. ${ }^{50}$ Other studies support that essential oil constituents (for herbals in general) relax rather than contract uterine tissues. ${ }^{51-53}$ Ferulic acid, another constituent found in black cohosh ${ }^{54,55}$, is poorly soluble in water ${ }^{56}$ and has been shown to decrease spontaneous activities from rat uterine smooth muscle in situ. . $^{7}$

In an experiment preparing lipid-free plant extract samples of Ethiopian pepper Xylopia aethiopica and African basil Ocimum gratissimum, the remaining phytochemical constituents, including saponins, tannins (a polyphenolic biomolecule), and alkaloids all produced an oxytocic activity on guinea pig isolated uterine tissues. ${ }^{58}$ Black cohosh also contains triterpene glycosides (saponins), tannins, and alkaloids. ${ }^{54,55}$ Saponins are both water and lipid soluble ${ }^{59}$, tannins are water soluble ${ }^{60}$, and alkaloids, as they exist in plant tissues, allow for the formation of salts as mineral acids or organic acids; they are also water soluble..$^{61,62}$

The saponin constituent can be considered a major contributor to the contraction of uterine smooth muscle, as isolated saponins from the soap tree Quillaja saponin, prepared the same way as the aqueous extracts reported herein, strongly contracted isolated mouse uterine tissues. $^{63}$ This action could well mask the effects of other active constituents. For example, tannins have been shown to antagonize uterine contractions in rat uteri in a dose-dependent manner. ${ }^{64}$ Responses from a variety of plant alkaloids are also reported to be quite diverse, with some alkaloids contracting isolated uterine tissues ${ }^{65,66}$, while others apparently employ different mechanisms of action, resulting in the relaxation of precontracted tissues. ${ }^{67,68}$

Clearly, the possible summing of potential contractile and relaxation activities from uterine smooth muscle reflects the diversity of bioactive constituents found within the administered herbals. This needs to be considered in conjunction with their signalling mechanisms across the plasma membranes via a variety of receptors (e.g. autonomic, oxytocin, prostaglandin, oestrogen) and ion channels. ${ }^{69}$

The contractile forces produced by the partridgeberry extracts were very strong. Of the four herbals tested, partridgeberry produced average uterine contractile forces of $139 \%$ of its oxytocin response, and these were even greater than those produced from black cohosh $(115 \%$ oxytocin response). While partridgeberry does contain saponins, ${ }^{67,33,34}$ information is not yet available on its distribution as compared to black cohosh.

The contractile forces produced by the motherwort (Leonurus cardiaca) extracts were also strong ( $94.5 \%$ oxytocin response), but not as forceful as those produced by partridgeberry or black cohosh (see Figure 3). Several compounds have been identified in motherwort and include monoterpenes, diterpenes, triterpenes (saponins), alkaloids, phenylpropanoids, flavonoids and phenolic acids, as well as volatile oils, sterols and tannins. ${ }^{33,71,72}$ Positive uterine contractile responses have been recorded in in vitro from rabbit and rat uteri using herbal extracts from the closely related Chinese motherwort Leonurus aretemisiae. ${ }^{73}$

Some of the constituents from L. aretemisiae have been isolated and demonstrate biological activity. For example, the flavonoid genkwanin has been shown to contract isolated strips of rat uterine tissue as effectively as oxytocin, ${ }^{74}$ and also the alkaloid stachydrine has been shown to contract isolated strips of guinea pig uterine tissues. ${ }^{75}$ Another alkaloid, leonurine, has also been shown to contract isolated strips of rat uterine tissues, ${ }^{76}$ but in contrast, and using a different target tissue, leonurine produced relaxation in precontracted rat aortic arterial rings. ${ }^{77}$

The last of the herbal induction tincture ingredients, cramp bark also contracted the isolated uterine smooth muscle strips comparable to those produced by an oxytocin $10^{-5} \mathrm{M}$ response (90.1\%). Even though cramp bark does contain saponins ${ }^{78}$ cramp bark has also been reported to produce bradycardia, hypotension, and reduce myocardial contractility ${ }^{79}$ and has been observed to reduce muscle pain associated with uterine contractions after birth or during menstruation..$^{30,31,80}$ These 
reports are in contrast to the results presented herein showing cramp bark as producing forceful uterine contractions (Figure 4). While they are observed to be less forceful than those produced from black cohosh and partridgeberry, the differences are not significant. The lower solubility of cramp bark itself is likely a contributing factor as all four herbals concentrations were made from equal dry stock masses. Again, these results indicate a diversity of chemical constituents interacting with unique signalling mechanisms across muscle cell membrane to produce a variety of systemic effects.

It is reasonable that saponin constituents found within the four herbs are involved in uterine smooth muscle contractility. It has been proposed that the hydrophobic portions of saponin molecules form insoluble complexes with membrane cholesterol, leading to saponin-cholesterol micelles which disrupt the lipid bilayer of cells. ${ }^{81,82}$ This results in invaginations and subsequent pore formation in the membrane ${ }^{83,84}$, allowing for the influx of extracellular calcium ions and the subsequent initiation of contractions.

Since herbal induction tinctures are orally consumed, the bioavailability of the saponins must be considered. Saponin molecules are amphipathic in that they have both a hydrophobic region (aglycone) and a hydrophilic region (glycone). The glycone (sugar) region of the molecule is digested from the sapogenin region (aglycone region) possibly due to activities of the gastric mucosa ${ }^{85}$ or hydrothermolysis ${ }^{86}$ within the gastrointestinal tract of the consumer. It is the resulting sapogenin that is likely absorbed via self-micellation, which then enhances their nearness to intestinal cells for absorption. ${ }^{87}$ The efficiency of this process is an area of continued study and may be varied due to the variety of sugar moieties and sapogenin regions within a given plant species. ${ }^{69}$

Thus, the contractile responses produced from each of the four herbals could indeed be anticipated as all four tested herbals contain saponins. The observed variation in contractile responses among the four different herbals is expected due to their companion phytochemical constituents, potentially resulting in some synergistic and/or attenuating responses from the uterine tissues. Isolated agonists studies of these active compounds and their receptor antagonists would help elucidate which uterine contractile and/or relaxation signalling pathways have been activated. ${ }^{69,88}$

Even though there is a reported history of using these herbal constituents to stimulate or relax uterine contractions in humans, the need to collect more empirical evidence to support or dispute these claims is still warranted. And it is worth noting that the study herein did not examine the combined effect of these herbs, which could have a synergistic effect. Before formal recommendations can be made for the use of these herbs in pregnant patients, future research must consider both effectiveness as well as safety of their use in pregnant populations. Just as administering oxytocin carries a risk for uterine hyperstimulation and subsequent fetal distress, the use of any uterotonic should be given with caution within a framework of shared decision making between the provider and patient. Notably, the number one reason cited by certified nurse-midwives in the United States that do not use herbal preparations in their protocols is the lack of research supporting the value of their use. ${ }^{8}$ As isolated uterine tissue investigations do provide some empirical support, the results must be carefully interpreted considering the qualitative and quantitative parameters employed in any given experiment.

\section{CONCLUSIONS}

This study investigated the individual contractile responses of the raw constituents of an herbal induction tincture on isolated mouse uterine tissues. It was found that all four constituents (black cohosh, cramp bark, partridgeberry, motherwort) did significantly increase the force of contractions when compared to the tissues " 0 " treatment (or spontaneous motility). These herbal extracts produced contractile responses that were comparable to those produced from oxytocin at $10^{-5} \mathrm{M}$.

This study provides empirical support for the use of these plants as herbal uterotonics, and it is plausible that these results, collected in vitro, may support the use of such a tincture to enhance or augment labor in vivo. However, this research is limited in its ability to address the biologic activity these herbs might have on human uteri in vivo and does not address any potential adverse effects or safety parameters for either pregnant patients or their fetuses. Consideration of the types of biologically active constituents found in each herbal, their concentrations, solubilities, cell signalling pathways, and potential to interact in a synergistic or attenuating manner must be considered.

\section{ACKNOWLEDGEMENTS}

This research was carried out at Bethel University and was made possible by contributions from both the Division of Natural and Behavioral Sciences, and the Department of Biological Sciences.

\section{REFERENCES}

1. WHO recommendations: induction of labor at or beyond term. Geneva: World Health Organization; 2018. License: CC BY-NC-SA3.0 IGO. https://books.google.com/books?id=hHOyDwAAQBAJ\&lpg= PR5\&ots=edytXfFvTe\&dq=WHO $\%$ 20recommendations $\% 3 A \% 20$ induction \%20 of\%20labor\%20at \%20 or \%20beyond \%20term. \%20 Geneva \%3A \% 20World \% 20Health \% 20Organization \% 3B \% 20 2018. \%20License \%3A\%20CC\%20BY-NC-SA\%203.0\%20IGO.\&lr $\& p g=P P 1 \# v=$ thumbnail $\& q \& f=$ false

2. Seijmonsbergen-Schermers $A E$, van den Akker $T$, Rydahl $E$, Beeckman K, Bogaerts A, Frith LL et al. Variations in use of childbirth interventions in 13 high-income countries: A multinational crosssectional study. PLOS Medicine 2020;17(5): e1003103. https://doi. org/10.1371/journal.pmed.1003103

3. Ely D, Hamilton B. Trends in Fertility and Mother's Age at First Birth Among Rural and Metropolitan Counties: United States, 2007-2017. National Center for Health Statistics Data Brief No. 323, October 2018. https://www.cdc.gov/nchs/products/ databriefs/db323.htm?utm_source=STAT+Newsletters\&utm_ campaign=cf4f33524b-MR_COPY_08\&utm_medium=email\&utm term=0_8cab1d7961-cf4f33524b-149692869

4. Vlieghe P, Lisowski V, Martinez J, Khrestchatisky M. Synthetic therapeutic peptides: science and market. Drug Discov Today 2010;15(1/2)40-56. https://doi.org/10.1016/j.drudis.2009.10.009

5. Eisenberg DM, Kessler RC, Foster C, Norlock FE, Calkins DR, Delbanco TL. Unconventional medicine in the United States prevalence, costs, and patterns of use. NEJM 1993;328:246-52. https://www.nejm.org/doi/full/10.1056/NEJM199301283280406

6. Murray T, Kelsberg G, Safranek S. Do any folk remedies or herbals help induce labor? Fam Pract 2008;57(8):542-4. http://hdl.handle. net/10355/3782

7. Hall HG, Griffiths D, Mckenna. Midwives' support for complementary and alternative medicine: A literature review. Women Birth 2012;25(1):4-12. https://doi.org/10.1016/j.wombi.2010.12.005

8. McFarlin B, Gibson M, O'Rear J, Harman P. A national survey of herbal preparation use by nurse-midwives for labor stimulation. J Midwifery 1999;44(3):205-16. https://doi.org/10.1016/S00912182(99)00037-3

9. Glover D, Amonkar M, Rybeck B, Tracy T. Prescription, over-thecounter, and herbal medicine use in a rural, obstetric population. Am J Obstet Gynecol 2003;188(4):1039-45. https://doi.org/10.1067/ mob.2003.223

10. Hastings-Tolsma M, Terada M. Complementary medicine use by nurse midwives in the U.S. Complement Ther Clin Pract 2009;15(4):212-9. https://doi.org/10.1016/j.ctcp.2009.06.016 
Neuenschwander C, et al.: An Investigation into the Use of an Herbal Labor Induction Tincture Containing Black Cohosh, Cramp Bark, Partridgeberry, and Motherwort on Contractile Responses Produced from Isolated Strips of Mouse Uterine Tissues

11. Holst $L$, Wright $D$, Haavik $S$, Nordeng $H$. The use and the user of herbal remedies during Pregnancy. J Altern Complement Med. 2009;15(7) http://doi.org/10.1089/acm.2008.0467

12. Dennehy C, Tsourounis C, Bui L. King T. The use of herbs by California midwives. J Obstet Gynecol Neonatal Nurs. 2010;39(6):684-93. https://doi.org/10.1111/j.1552-6909.2010.01193.x

13. Dawood MY. Novel approach to oxytocin induction-augmentation of labor application of oxytocin physiology during pregnancy. Adv Exp Med Biol 1995;395:585-94. https://europepmc.org/article/ $\mathrm{med} / 8714022$

14. Steinberg D, Beal M. Homeopathy and women's healthcare J Obstet Gynecol Neonatal Nurs 2003;32:207-14. https://doi. org/10.1177/0884217503252125

15. Page K, McCool WF, Guidera M. Examination of the pharmacology of oxytocin and clinical guidelines for use in labor. J Midwifery Womens Health 2017;62(4):425-33. https://doi.org/10.1111/ jmwh.12610

16. Berger J, DeGolier T. Pharmacological effects of the aqueous extract of Caulophyllum thalictroides (blue cohosh) on isolated Mus musculus uteri. BIOS 2008;79(3):103-14. https://www.jstor.org/ stable/25433832

17. Olson A. and DeGolier T. Research article: contractile activity of Rubus idaeus extract on isolated mouse uterine strips. BIOS 2016;87(2):39-47. https://doi.org/10.1893/BIOS-D-15-00001.1

18. Quam N, Wu K, DeGolier T. Aqueous extracts of castor seed (Ricinus communis) increase the contractile activities of mouse uterine tissues in vivo. J Pharmacogn Phytochem 2016;5(4):40-5. https://scholar.google.com/scholar?hl=en\&as_sdt $=0 \% 2 \mathrm{C} 24 \& \mathrm{q}=0$ uam $+\mathrm{N} \% 2 \mathrm{C}+\mathrm{Wu}+\mathrm{K} \% 2 \mathrm{C}+$ DeGolier+T.+Aqueous +extracts + of $+\mathrm{ca}$ stor+seed $+\% 28$ Ricinus + communis $\% 29+$ increase+the+contractil e+activities+of+mouse+uterine+tissues+in+vivo.+J+Pharmacogn +Phytochem+2016\%3B5\% 284\%29\%3A40-5.extract+on+isolate $d$ +mouse+uterine+strips. + BIOS+2016\%3B87\%282\% 29\%3A3947.\&btnG

19. DeGolier T, Lyle C, Ortmann A. Aqueous extracts from evening primrose seeds (Oenethera biennis) contract isolated uterine tissues but have no effect on isolated cervical tissues. Int J Herb Med 2017;5(3):10-6. https://www.florajournal.com/archives/?year= $2017 \& \mathrm{vol}=5 \&$ issue $=3 \&$ part $=\mathrm{A}$

20. DeGolier T, Sam Adamson. Aqueous extracts of clary sage (Salvia sclarea) contract isolated strips of mouse uterine tissue. J Pharmacogn Phytochem 2021;10(2):59-64. https://www. phytojournal.com/archives/2021.v10.i2?page $=3$

21. Crankshaw DJ. Pharmacological technologies for the in vitro study of the uterus. J Pharmacol Toxicol 2001;45:123-40. DOI: 10.1016/ s1056-8719(01)00143-5

22. Allen E. The estrous cycle in the mouse. J Anat 1922; 30:297-371. https://doi.org/10.1002/aja.1000300303

23. Doherty L, Bromer J, Zhou Y, Aldad T, Taylor H. In utero exposure to diethylstilbestrol (DES) or bisphenol-A (BPA) increases EZH2 expression in the mammary gland: An epigenetic mechanism linking endocrine disruptors to breast cancer. Horm Cancer 2010:1(3):14655. doi: https://doi.org/10.1007/s12672-010-0015-9.

24. Burger $H$, Healy $D$, Vollenhover B. The ovary: basic principles and concepts. In: Felig P, Frohman L, editors. Endocrinology and Metabolism. $4^{\text {th }}$ ed. USA: McGraw-Hill, Inc; 2001.

25. Kitchen I. Textbook of in vitro practical pharmacology. Oxford: Blackwell Scientific Publications; 1984

26. Nidaullah H, Durrani FR, Ahmad S, Jan IU, Gul S. 2010. Aqueous extract from different medicinal plants as anticoccidial, growth promotive and immunostimulant in broilers. ARPN J Agric Biol Sci. 2010;5(1):53-9. https://www.cabdirect.org/cabdirect/ abstract/20103304281
27. Kaingu CK, Oduma JA, Kanui, T. Preliminary investigation of the contractile activity of Ricinus communis and Euclea divinorum extracts on isolated rabbit uterine strips. J Ethnopharmacol 2012;142:496-502. https://doi.org/10.1016/j.jep.2012.05.026

28. Husslein P, Fuchs AR, Fuchs F. Oxytocin and the initiation of human parturition: I. Prostaglandin release during induction of labor by oxytocin. Am J Obstet Gynecol 1981;141(5): 688-93. https://doi. org/10.1016/S0002-9378(15)33312-3

29. Weed, S. Herbal for the Childbearing Year. Wise Women. Ash Tree Publishing, Woodstock, New York.; 1986.

30. Westfall R. 2001. Herbal medicine in pregnancy and childbirth. Adv Ther 2001:18(1):47-55. https://link.springer.com/article/10.1007/ BF02850250

31. Duke J. The Green Pharmacy Herbal Handbook. St. Rodale/St. Martin's Press; 2000.

32. Kristin $S$, Newman A. Induction of labor with homeopathy: A case report. J Midwifery Wom Heal 2007;52(3):303-7. https://doi. org/10.1016/j.jmwh.2006.12.013

33. Noe J, Bove N, Janel K. 2002. Herbal tonic formulas for naturopathic obstetrics. Altern Complement Ther 2002;8(6):327-35. https://doi. org/10.1089/107628002761574617

34. Shinde $P$, Patil $P$, Bairagi. Herbs in pregnancy and lactation: $A$ review appraisal. Int J Pharm Sci Res. 2012;3(9):3001-6 http:// dx.doi.org/10.13040/IJPSR.0975-8232.3(9).3001-06

35. Fabricant DS, Farnsworth NW. The value of plants used in traditional medicine for drug discovery. Environ Health Perspect 2001;109(1) https://doi.org/10.1289/ehp.01109s169

36. Balunas MJ, Kinghorn AD. Drug discovery from medicinal plants. Life Sci. 2005;78(5):431-41. https://doi.org/10.1016/j.Ifs.2005.09.012

37. Wang $X, X u X$, Tao W, Li Y, Wang Y, Yang L. A Systems Biology Approach to Uncovering Pharmacological Synergy in Herbal Medicines with Applications to Cardiovascular Disease. eCAM. 2012 https://doi.org/10.1155/2012/519031

38. Alrasheid AA, Babiker MY, Awad TA. Evaluation of certain medicinal plants compounds as new potential inhibitors of novel corona virus (COVID-19) using molecular docking analysis. In Silico Pharmacol. 9, 10 (2021). https://doi.org/10.1007/s40203-020-00073-8

39. Bergeron C, Marston A, Gauthier R, Hostettmann K. Screening of plants used by North American Indians for antifungal, bactericidal, larvicidal and molluscicidal activities. Int J Pharmacogn 1996;34(4):233-42. https://doi.org/10.1076/phbi.34.4.233.13224

40. Sparg SG, Light ME, Van Staden J. Biological activities distribution of plant saponins. J Ethnopharmacol 2004;94:219-43. https://doi. org/10.1016/j.jep.2004.05.016.

41. Parham S, Kharazi AZ, Bakhsheshi-Rad HR, Nur H, Ismail AF, Sharif $\mathrm{S}$, et al. Antioxidant, antimicrobial and antiviral properties of herbal materials. Antioxidants 2020; 9(12):1309. https://doi.org/10.3390/ antiox9121309.

42. Yasmin AR, Chia SL, Looi QH, Omar AR, Noordin MM, Ideris A Herbal extracts as antiviral agents. Feed Additives 2020;115-32. https://doi.org/10.1016/B978-0-12-814700-9.00007-8.

43. Lin J. Applications and limitations of interspecies scaling and in vitro extrapolation in pharmacokinetics. J Ethnopharmacol 1998;26:120212. https://dmd.aspetjournals.org/content/26/12/1202.short?casa token=aJ7vrGppWFwAAAAA:PGxNF2MN8MPluJi9hKE1mIFhVQUNT1z8M9bzyRojQmVYaXsJrbCBqLO0Ghkv8D6P9HL1Y2wwA.

44. Fromm O, DeGolier T. 2021. The contractile capabilities of various herbal constituents on uterine smooth muscle and their shared constituent presence involved with anti-inflammatory/antioxidant mechanisms. J Pharmacogn Phytochem 10(4):28-37. https://www. phytojournal.com/archives/2021/vol10issue4/PartA/10-3-78-962. pdf. 
Neuenschwander C, et al.: An Investigation into the Use of an Herbal Labor Induction Tincture Containing Black Cohosh, Cramp Bark, Partridgeberry, and Motherwort on Contractile Responses Produced from Isolated Strips of Mouse Uterine Tissues

45. Hussein R, El-Anssary A. Plants secondary metabolites: the key Drivers of the pharmacological actions of medicinal plants. Published: November 5th 2018. https://www.intechopen.com/ books/herbal-medicine/plants-secondary-metabolites-the-keydrivers-of-the-pharmacological-actions-of-medicinal-plants.

46. Fitzpatrick LA. Alternatives to estrogen. Med Clin North America. 2003:87(5):1091-113. https://doi.org/10.1016/S00257125(03)00116-0.

47. Winterhoff $H$, Spengler B, Christoffel V, Butterweck V, Lohning A. Cimifuga extract BNO 1055: reduction of hot flashes and hints on antidepressant activity. Mauritas 44 (Suppl. 1) 2003, S51-S58. https://doi.org/10.1016/S0378-5122(02)00348-1.

48. Khan I, Abourashed E. Leung's encyclopedia of common natura ingredients used in food, drugs, and cosmetics, 3rd ed. Wiley; 2010

49. Burchum J, Rosenthal L, editors, 2019, Lehne's Pharmacology for Nursing Care. $10^{\text {th }}$ ed. Elsevier.

50. Bolle P, Mastrangelo S, Perrone F, Evandri M. Estrogen-like effect of Cimifuga racemosa extract sub-fraction as assessed by in vivo, ex vivo and in vitro assays. J Steroid Biochem Mol Biol 2007;107:2629. https://doi.org/10.1016/j.jsbmb.2007.03.044

51. Wang C, Caruso R. Alpha tocopherol inhibits activation of the $E$ isoform protein kinase $\mathrm{C}$ and NADPH oxidative mediated generation of superoxide anion radicals in lindane exposed myometrium. Annual Meeting for the Study of Reproduction. Pullman, WS 1999.

52. Ponce-Monter H, Campos M, Pérez S, Pérez C, Zavala M, Macías A, et al. Chemical composition and antispasmodic effect of Casimiroa pringlei essential oil on rat uterus. Fitoterapia 2008;79(6):446-50. https://doi.org/10.1016/j.fitote.2008.04.005.

53. Poyton C, Manchadi ML, Cheesman M, Lavidis N. Effects of lavender and linalool on neurotransmission and contraction of smooth muscle. Pharmacogn Commun 2015;5(3):217-26. https://www.researchgate.net/profile/Mary-Louise-Roy/publication/279517587_Effects_of_Lavender_and_Linalool_on_Neurotransmission_and_Contraction_of_Smooth_Muscle/links/5614946008aec622441054e3/ Effects-of-Lavender-and-Linalool-on-Neurotransmission-and-Contraction-of-Smooth-Muscle.pdf.

54. Jarry H, Harnischfeger, Duker E. Studies on the endocrine effects of the contents of Cimicifuga racemosa 2 . In vitro binding of compounds to estrogen receptors. Plant Med 1985;4:316-9. https:// doi.org/10.1055/s-2007-969500.

55. Shao $Y$, Harris $A$, Wang $M$, Zhang $H$, Cordell GA, Bowman $M$, et al. Triterpene glycosides from Cimicifuga racemosa. J Nat Prod 2000;63:905-10. Retrieved from https://doi.org/10.1021/np000047y.

56. Zhou Y, Lips A, Nanavaty FS, Bartolone JB. Stabilization of ferulic acid in cosmetic formulations. US patent 6,632,444 B1 (2003). https://patents.google.com/patent/US6632444/en.

57. Ozaki Y, Ma J-P. Inhibitory effects of tetramethylpyrazine and ferulic acid on spontaneous movement of rat uterus in situ. Chem Pharm Bull 1990; 38(6):1620-3. https://doi.org/10.1248/cpb.38.1620.

58. Okwu D, Omodamiro O. Effects of hexane extract and phytochemica content of Xylopia aethiopica and Ocimum gratissimum on the uterus of the guinea pig. Biol Res. 2005;3(2):40-4. https://doi. org/10.4314/br.v3i2.28589.

59. El Aziz, M, Ashour A, Melad A. A review of saponins from medicinal plants: chemistry, isolation, and determination. J Nanomed Res 2019:7(4):282-88. https://www.academia.edu/download/58981667/ JNMR-08-0019920190421-80737-1ctzyc7.pdf.

60. Chung KT, Wong TY, Wei $\mathrm{Cl}$, Huang YW, Lin Y. Tannins and human health: a review. Crit Rev Food Sci Nutr 1998;38(6):421-64. https:// doi.org/10.1080/10408699891274273.

61. Yubin J, Miao Y, Wang B, Zhnag Y. The extraction, separation and purification of alkaloids in the natural medicine. J Chem Pharm Res 2014; 6(10:338-345. https://www.jocpr.com/articles/the-extractionseparation-and-purification-of-alkaloids-in-the-natural-medicine.pdf
62. Bribi N. Pharmacological activity of alkaloids: A review. Asian J Bot 2018;1:doi:10.63019/ajr.vli2.467. https://www.researchgate.net/ profile/Noureddine-Bribi/publication/324476579_Pharmacological_ activity_of_Alkaloids_A_Review/links/5acf2dfeaca2723a3344e20a/ Pharmacological-activity-of-Alkaloids-A-Review.pdf.

63. Bristol B, DeGolier T. Quillaja saponins are a potent contractor of uterine smooth muscle tissue in vitro. J Pharmacogn Phytochem 2018;7(5):1252-58. https://www.phytojournal.com/archives/2018/ vol7issue5/PartV/7-4-620-112.pdf.

64. Calixto J, Nicolau M, Rae G. Pharmacological Actions of Tannic Acid. I. Effects on Isolated Smooth and Cardiac Muscles and on Blood Pressure. Planta Med 1986;52(1):32-5. https://doi. org/10.1055/s-2007-969061

65. King $C$, Kong $Y$, Wong $N$, Yeung $H$, Fong H, Sankawa. Uterotonic Effect of Evodia rutaecarpa Alkaloids. J Nat Prod 1980;43(5): 577-82. https://pubs.acs.org/doi/pdf/10.1021/np50011a008?casa token=i GegnDgP00AAAAA:Hcfl28EqOoHAJkiOPehRKYwYHBHOgKydr9XJ LFWUfZ34L7LwW9sWJroNwjC9mDRWUBieLgVofnKWSO.

66. Liu J, Peng C, Zhou QM, Guo L, Liu Z-H, Xiong L. Alkaloids and flavonoid glycosides from the aerial parts of Leonurus japonicus and their opposite effects on uterine smooth muscle. Phytochemistry 2018;145:128-36. https://doi.org/10.1016/j. phytochem.2017.11.003.

67. D'ocon P, Blazquez M, Bermejo A, Anselmi E. Tetrandrine and isotetrandrine, two bisbenzyltetrahydroisoquinoline alkaloids from Menispermaceae, with rat uterine smooth muscle relaxant activity. J Pharm Pharmacol 1992;44(7):579-82. https://doi. org/10.1111/j.2042-7158.1992.tb05468.x.

68. Ivorra M, Martinez F, Serrano A, D'ocon. Different Mechanism of Relaxation Induced by Aporphine Alkaloids in Rat Uterus. J Pharm Pharmacol 1993;45(5):439-43. https://doi. org/10.1111/j.2042-7158.1993.tb05572.x.

69. Gruber C, O'Brien M. Uterotonic plants and their bioactive constituents. Planta Med 2011;77:207-20. https://doi. org/10.1055/s-0030-1250317.

70. Beck B. Ethnobotanical studies of Mitchella repens L. (Rubiaceae) Ph D Dissertation. Miami University, Oxford, Ohio; 1999.

71. Wojtyniak K, Szymanski M, Matlawska I. Leonurus cardiaca L. (Motherwort): A Review of its Phytochemistry and Pharmacology. Phytother Res 2013;7(8):1115-20. https://doi.org/10.1002/ptr.4850.

72. Zhang $R H$, Liu ZK, Yang DS, Zhang XJ, Sun HD, Xiao WL. Phytochemistry and pharmacology of the genus Leonurus: The herb to benefit the mothers and more. Phytochemistry 2018;147:167183. https://doi.org/10.1016/j.phytochem.2017.12.016.

73. Kong $\mathrm{YC}, \mathrm{Ng} \mathrm{KH}$. Stimulatory effect of Leonurus artemisia (I-Mu Ts'ao) on the contraction of human myometrium in vitro. Experientia 1974;30:1281-82. https://doi.org/10.1007/BF01945186.

74. Fan J, Wei F, Zhang Y, Su H, Ji Z, He J, et al. Combining SpragueDawley rat uterus cell membrane chromatography with HPLC/MS to screen active components from Leonurus artemisia. Pharm Biol 2016;54(2):279-84. https://doi.org/10.3109/13880209.2015. 1033562 .

75. Dai L, Xie X, Sun C, Ao H, Dong Y, Peng C. Effect of alkaloid monomer of Yimucao injection on isolated smooth muscle of uterus. Nat Prod Res Dev 2016;28:1633-38. http://www.trcw. ac.cn/EN/10.16333/j.1001-6880.2016.10.025.

76. Kong $\mathrm{Y}$, Yeung $\mathrm{H}$, Cheung $\mathrm{Y}$, Hwang J, Chan $\mathrm{Y}$, Law $\mathrm{Y}$, et al. Isolation of the uterotonic principle from Leonurus artemisia, the Chinese motherwort. Am J Chin Med 1976;4:373-82. Retrieved from https://doi.org/10.1142/S0192415X76000470.

77. Chen CX, Kwan CY. Endothelium-independent vasorelaxation by leonurine, a plant alkaloid purified from Chinese motherwort. Life Sci 2001;68(2):953-960. https://doi.org/10.1016/S00243205(00)00987-5. 
Neuenschwander C, et al.: An Investigation into the Use of an Herbal Labor Induction Tincture Containing Black Cohosh, Cramp Bark, Partridgeberry, and Motherwort on Contractile Responses Produced from Isolated Strips of Mouse Uterine Tissues

78. Rychlińska I. Sterols and triterpenes in Viburnum opulus L. leaves. Herba Pol 2008;54:59-65. https://www.infona.pl/ resource/bwmeta1.element.agro-article-6e4bfdf9-03a9-4c3185e6-618824121094.

79. Nicholson JA, Darby TD, Jarboe CH. Viopudial, a hypotensiveand smooth muscle antispasmodic from Viburnum opulus. EBM 1972;140(2):45761. https://doi.org/10.3181\%2F00379727-140-36479.

80. Dietz, BM; Hajirahimkhan A; Dunlap TL, Bolton JL. Botanicals and their bioactive phytochemicals for women's health. Pharmacol Rev 2016;68(4):1026-1073. https://doi.org/10.1124/pr.115.010843.

81. Baumann E, Stoya G, Völkner A, Richter W, Lemke C, Linss W. Hemolysis of human erythrocytes with saponin affects the membrane structure. Acta Histochemica. 2000;102(1):21-35. https://doi.org/10.1078/0065-1281-00534

82. Francis G, Kerem Z, Makkar HP, Becker K. The biological action of saponins in animal systems: A review. BJN 2002;88(6):587-605. https://doi.org/10.1079/BJN2002725

83. Bangham A, Horne R. Action of saponins on biological cells membranes. Nature 1962;196:952-53. https://doi.org/10.1038/196952a0.
84. Das TK, Banerjee D, Chakraborty D, Pakhira MC, Shrivastava B, Kuhad RC. Saponin: role in animal system. Vet World 2012;5(4):24854. https://doi.org/10.5455/vetworld.2012.248-254.

85. del Hierro H, Herrera T, Fornari T, Reglero G, Martin D. The gastrointestinal behavior of saponins and its significance for their bioavailability and bioactivities. J Funct Foods 2018;40:484-97. https://doi.org/10.1016/j.jff.2017.11.032.

86. Kim $Y$, Higuchi R, Komori T. Thermal degradation of glycosides $v$. hydrothermolysis of triterpenoids and steroid glycosides. Liebigs Annaken Der Chemia 1992;5:453-59. https://doi.org/10.1002/ jlac.199219920181.

87. Bottcher S, Drusch S. Saponins - self-assembly and behavior at aqueous interfaces. Adv Colloid Interface Sci 2017; 243:105-113. https://doi.org/10.1016/j.cis.2017.02.008.

88. Young R. Myocytes, myometrium, and uterine contractions. Ann N Y Acad Sci 2007;1101:72-84. https://www.researchgate.net/profile/ Roger-Young/publication/6385527_Myocytes_Myometrium_ and_Uterine_Contractions/links/59b00c35aca2728472cccd6c/ Myocytes-Myometrium-and-Uterine-Contractions.pdf.

\section{GRAPHICAL ABSTRACT}
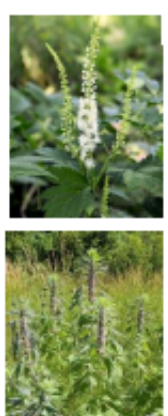

Plants of interest
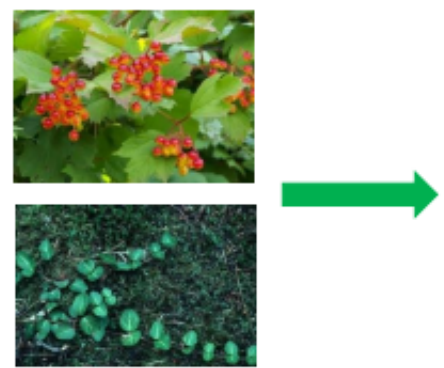

\section{-}

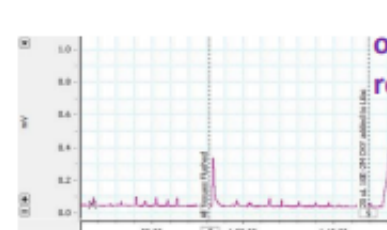

oxytocin

response

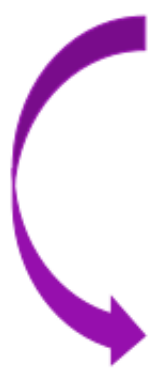

. .0

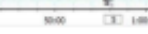

Increased

tension

comparable to oxytocin
Individual aqueous extracts
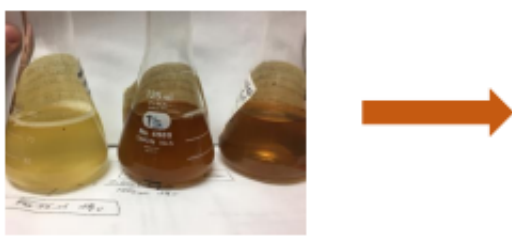

herbal response
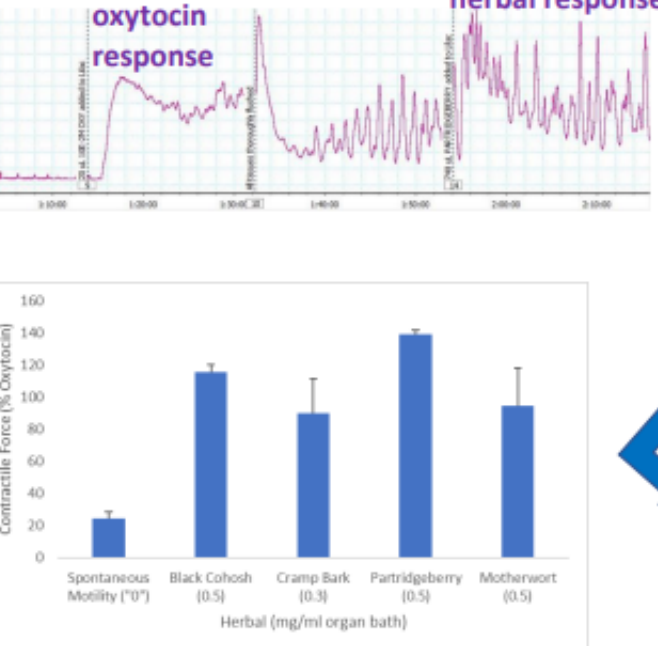

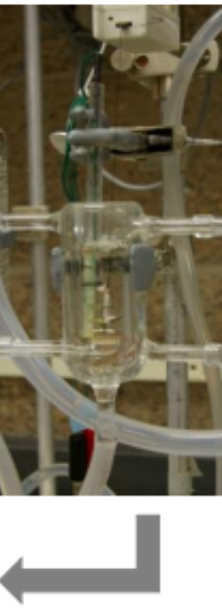

Direct

application to isolated mouse uterine tissue 


\section{ABOUT AUTHORS}
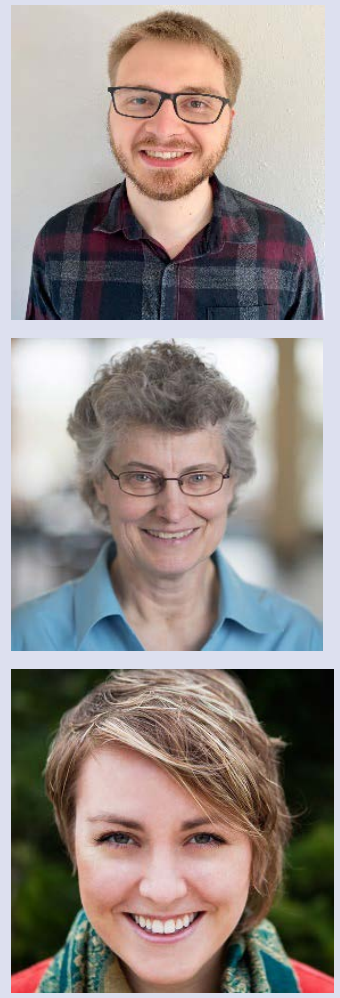

Clayton Neuenschwander holds a baccalaureate in Biology from Bethel University where he graduated magna cum laude in 2019. He is currently a student at the University of Minnesota Medical School pursuing a degree in allopathic medicine with a specific interest in diagnostic radiology. Areas of interest include radiomics and diagnostic algorithms.

Teresa DeGolier is currently Professor of Biology at Bethel University. She graduated with a Ph D in Animal Physiology from the University of Minnesota, USA in 1994 and since has been teaching animal physiology, human physiology, and organismal biology. Her research is focused on how medicinal plants regulate uterine smooth muscle contractions.

Katrina Wu is a certified nurse-midwife and assistant professor at Bethel University, where she educates future midwives. She received her Master of Science in Nursing, specializing in nurse-midwifery, from Vanderbilt University, and she is currently pursuing her Ph.D. at the Medical University of South Carolina. Her practice expertise is in developing women's healthcare services and attending births in the home and birth center settings. Her current research interests include addressing perinatal outcome disparities by improving access to prenatal care services and exploring innovative models for care delivery.

Cite this article: Neuenschwander C, Wu K, DeGolier T. An Investigation into the Use of an Herbal Labor Induction Tincture Containing Black Cohosh, Cramp Bark, Partridgeberry, and Motherwort on Contractile Responses Produced from Isolated Strips of Mouse Uterine Tissues. Pharmacogn J. 2021;13(6): 1478-1487. 